\title{
Role of Generation on Successful DNA Delivery of PAMAM- (Guanidino)Neomycin Conjugates
}

Nina Bono, ${ }^{\dagger, \perp}$ Chiara Pennetta, ${ }^{\ddagger}, \perp$ Maria Cristina Bellucci, ${ }^{\S}$ Aurora Sganappa, ${ }^{\dagger}$ Chiara Malloggi, ${ }^{\dagger}$ Gabriella Tedeschi, " Gabriele Candiani, ${ }^{*}$, , $\neq 0$ and Alessandro Volonterio $*$,

${ }^{\dagger}$ Politecnico di Milano Research Unit, National Interuniversity Consortium of Materials Science and Technology-INSTM, Via Mancinelli 7, 20131 Milan, Italy

${ }^{\ddagger}$ Department of Chemistry, Materials, and Chemical Engineer “G. Natta”, Politecnico di Milano, Via Mancinelli 7, 20131 Milan, Italy

${ }^{\S}$ Department of Food, Environmental and Nutritional Sciences, Università degli Studi di Milano, Via Celoria 2, 20133 Milan, Italy

"Department of Animal Pathology, Hygiene and Veterinary Public Health, Università degli Studi di Milano, Via Celoria 10, 20133 Milan, Italy

\section{Supporting Information}

ABSTRACT: The decoration of polyamidoamine (PAMAM) dendrimers with some functional moieties holds promises for improving the gene-delivery behavior of the resulting polyplexes. Herein, we reported the synthesis and the development of nonviral gene vectors built on an array of PAMAMs, spanning generation 2 (G2), G4, and G7, specifically tethered with multivalent neomycin (Neo) or guanidinoneomycin (GNeo). Following a thorough chemical characterization by means of NMR and MALDI analyses, the ability of PAMAM-(G)Neo conjugates to serve as transfectants was investigated. First, we demonstrated that every PAMAM, whether or not tethered with Neo (or GNeo), exhibited greater DNA packing ability than the gold standard transfectant $25 \mathrm{kDa} b$ PEI. Measurements of the colloidal properties showed that PAMAMs, when mixed with
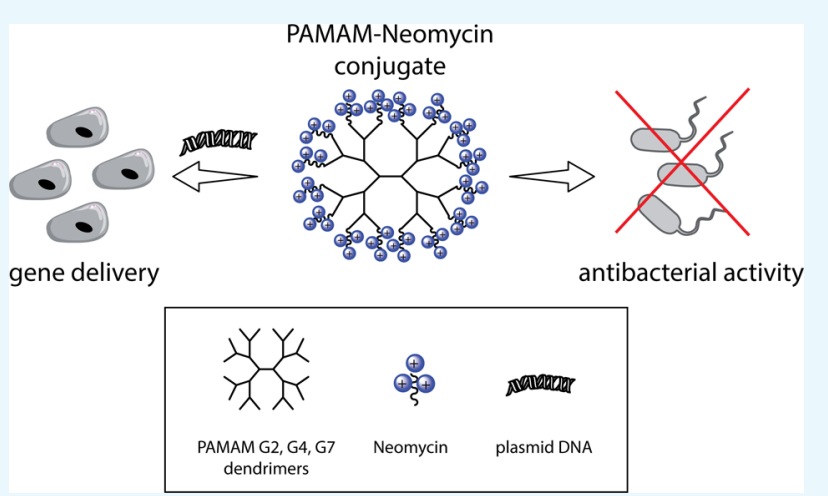
plasmid DNA (pDNA) as a function of the nitrogen-to-phosphate ratio $(\mathrm{N} / \mathrm{P})$, allowed preparing complexes of $\approx 150-300 \mathrm{~nm}$ in diameter with a positive surface charge of $\approx+20-35 \mathrm{mV}$, strictly dependent on the PAMAM generation. The conjugation with Neo affected the DNA release behavior from PAMAM-based polyplexes and their ultimate transfection efficiency. When low generation PAMAM G2 was tethered with $\mathrm{Neo}$, we obtained the most efficient transfectants, with remarkable antibacterial activity against Gram negative bacteria. It is worth noting that pDNA/PAMAM-(G)Neo nanoassemblies, which were tested at the optimal N/P, invariably showed better transfection efficiency than $25 \mathrm{kDa} b \mathrm{PEI}$, along with low cytotoxicity in both HeLa and COS-7 cells. Altogether, these results underline the potential of such PAMAM- $(\mathrm{G})$ Neo dendrimers as promising vehicles for efficient gene delivery into cells.

\section{INTRODUCTION}

Dendrimers are a class of synthetic and well-structured polymers with excellent monodispersity and symmetrical three-dimensional (3D) branched architecture. ${ }^{1-3}$ Because of such structural perfection, along with being highly branched, the presence of multiple peripheral end groups and internal cavities, and the relative ease of synthesis (overall for low generations), dendrimers have attracted much interest for a number of applications. ${ }^{4,5}$ For instance, they have been used as antibacterial agents ${ }^{6,7}$ and antimicrobial surface coatings, ${ }^{8}$ nanocarriers for smart drug delivery, ${ }^{9-13}$ diagnostic agents, ${ }^{14,15}$ and theranostics overall. ${ }^{16}$ Above all, dendrimers have attracted great attention as a valid alternative to immunogenic viral vectors for the delivery of nucleic acids (NAs). ${ }^{17}$ Polyamidoamine (PAMAM) dendrimers have been probably the most explored, because of some unique features, such as (1) their inherent ability to condense polyanionic NAs into the so-called dendriplexes, (2) the efficient cellular uptake of PAMAM dendriplexes on different cell lines and their localization into endo-lysosomes, (3) the presence of tertiary amines in the backbone responsible for the "proton sponge" effect favoring endosomal escape, (4) the presence of outer primary amino groups, cationic at physiological $\mathrm{pH}$, and (5) their nonimmunogenicity. ${ }^{18}$ Although not very effective for siRNA delivery, structurally flexible PAMAMs have been used for gene silencing purposes as well. ${ }^{19,20}$ However, some issues have been hampering their applications to a greater extent. Indeed, as gene-delivery systems, PAMAM dendrimers have proven to

Received: October 11, 2018

Accepted: April 2, 2019

Published: April 15, 2019 

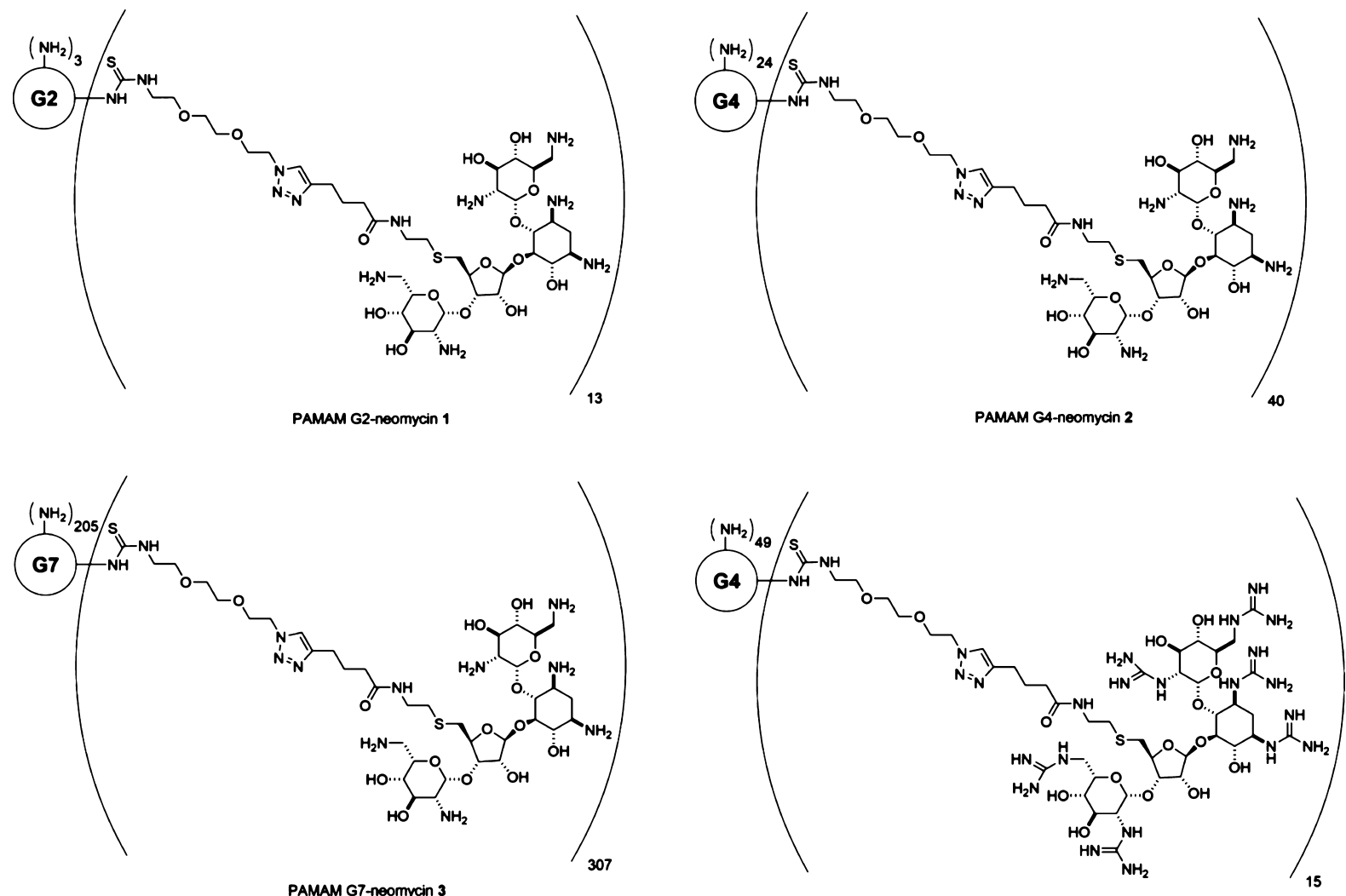

PAMAM G4-guanidinoneomycin 4

Figure 1. Schematic representation of PAMAM G2-, G4-, G7-Neo, and PAMAM G4-GNeo conjugates.

suffer from the transfection efficiency and cytotoxicity paradox. High generation dendrimers are much more efficient transfectants, though they display severe cytotoxicity. Besides, the synthesis of high generation PAMAM dendrimers is unfortunately time-consuming and expensive, which largely limit their biomedical applications. ${ }^{21}$ On the other hand, low generation dendrimers are notoriously less toxic but less effective because of the poor plasmid DNA (pDNA) complexation/decomplexation ability. In order to make dedrimeric PAMAMs ideal gene-delivery vectors, it has been reported the functionalization of high generation PAMAMs with different ligands such as lipids, fluorous compounds, ${ }^{22,23}$ amino acids, polysaccharides, proteins and peptides, other polymers, and some cationic moieties, ${ }^{17}$ while low generation PAMAMs have been nanoclustered through covalent and non-covalent bonding. $^{20,24-26}$ In this contest, we have recently designed a new class of multifunctional PAMAM-aminoglycoside (AG) conjugates $^{27}$ obtained by grafting three different AGs, neamine (Nea, bearing three amino groups), paromomycin (Paro, bearing five amino groups), and neomycin $\mathrm{B}$ (Neo, bearing six amino groups) antibiotics on the outer primary amino groups of PAMAM generation 4 (PAMAM G4). Such multifunctional PAMAM G4-AGs displayed high gene-delivery efficiency along with negligible cytotoxicity, the PAMAM G4-Neo derivative being the most performing at low $\mathrm{N} / \mathrm{P}$.

Herein, we report a step further in the structure-function relationship analysis of such dendrimers, that is, the evaluation of the effects of different PAMAM generations, namely G2, G4, and G7, on the efficiency and cytotoxicity of PAMAM-Neo conjugates (PAMAM G2-, G4-, G7-Neo). Starting from PAMAM G2, G4, and G7, we synthetized three polymeric conjugates with Neo using isothiocyanate/amine click chemistry (Figure 1). Moreover, along with PAMAM-Neo conjugates, we have synthetized also PAMAM G4-guanidinoneomycin (PAMAM G4-GNeo) in order to study the influence of guanidinylation on the gene transfection efficiency of these dendrimers. The antibacterial effectiveness of the resulting polymers and polyplexes was evaluated as well.

\section{RESULTS AND DISCUSSION}

Since their first use in $1993,{ }^{28}$ PAMAM dendrimers have been extensively investigated as non-viral gene-delivery vectors. Being dendrimers, PAMAMs possess a well-defined structure, characterized by many functional end groups, responsible for high solubility (especially at low generations) and reactivity and inner cavities serving as binding sites for drugs. In spite of their fairly good transfection efficiency (especially at high generations), the widespread use of PAMAMs as delivery agents is limited because of their inherent toxicity and high cost. On the other hand, the chemical reactivity of primary amino end groups of PAMAMs allows for and easy functionalization with specific moieties to give rise to more effective gene vectors.

In this context, we propose the synthesis of an array of PAMAM dendrimers, namely, PAMAM G2, G4, and G7, decorated with the (guanidino)neomycin moiety (hereinafter referred to as $(\mathrm{G}) \mathrm{Neo}$ ). After a thorough chemical characterization to calculate the grafting yield, we evaluated and compared the performances of PAMAM- $(\mathrm{G}) \mathrm{Neo}$ dendrimers with those of the parent pristine PAMAMs in transfection, in order to shed light on the role of the dendrimer generation on grafting and thus on their ultimate transfection efficiency in 
Scheme 1. Synthesis of PAMAM-(G)Neo Conjugates 1-4
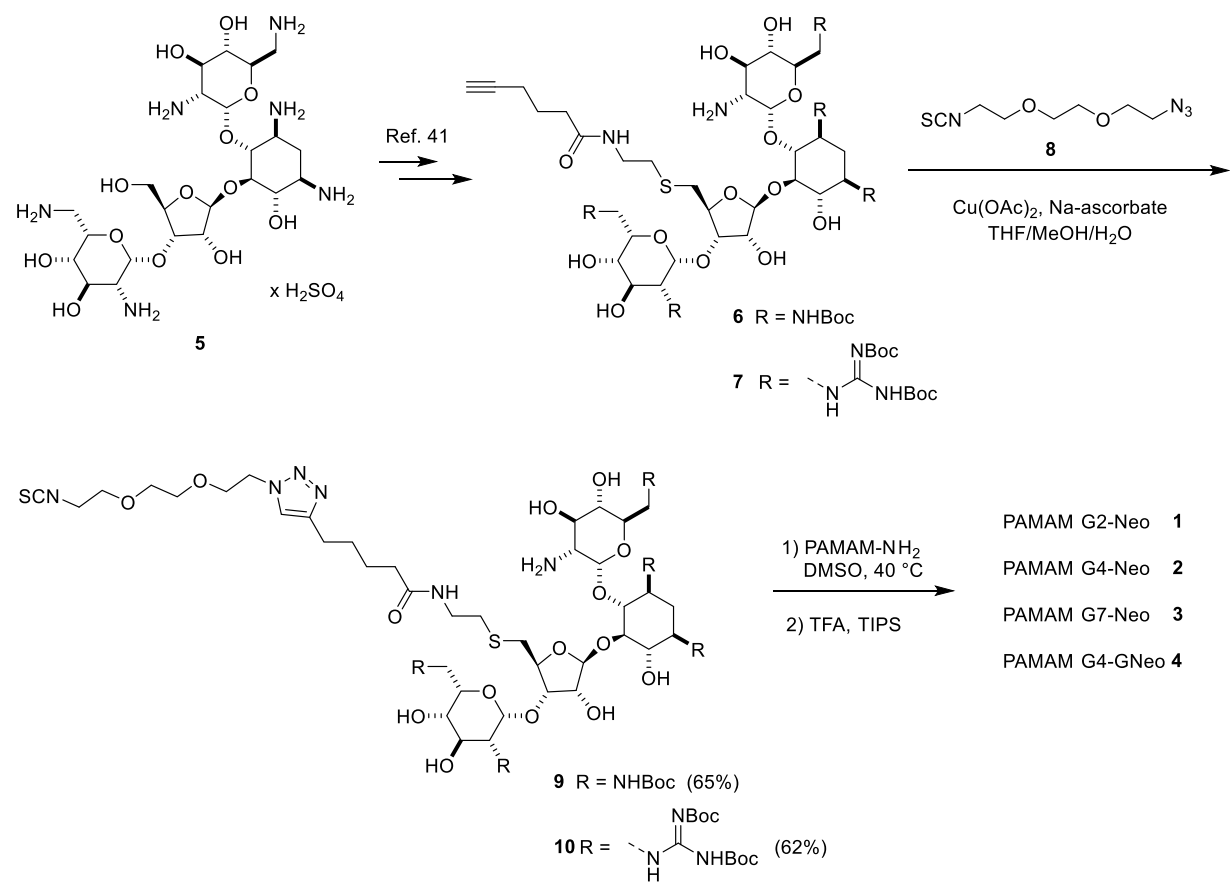

Table 1. Degree of Grafting Calculated by ${ }^{1} \mathrm{H}$ NMR Integrations and MALDI Mass Analysis

\begin{tabular}{|c|c|c|c|c|c|c|c|}
\hline & \multicolumn{2}{|c|}{$\begin{array}{c}{ }^{1} \mathrm{H} \text { NMR relative } \\
\text { integration }\end{array}$} & & & & \multicolumn{2}{|c|}{$m / z$ value } \\
\hline Dendrimer & $\begin{array}{c}(\mathrm{G}) \mathrm{Neo} \\
\text { anomeric } \\
\text { proton } \\
\text { H' }\end{array}$ & $\frac{1}{+}$ & $\begin{array}{l}\text { Hydrogens } \\
\text { belonging } \\
\text { to the } \\
\text { dendrimer }\end{array}$ & $\begin{array}{l}\text { Calculated } \\
\text { hydrogens } \\
\text { belonging } \\
\text { to the } \\
\text { linker }\end{array}$ & $\begin{array}{c}\text { \# of } \\
\text { (G)Neo } \\
\text { grafted }^{\text {b }}\end{array}$ & $\begin{array}{l}\text { Experimental } \\
\text { value }\end{array}$ & $\begin{array}{c}\text { Calculated } \\
{\left[\mathrm{M}+\mathrm{H}^{+}\right]}\end{array}$ \\
\hline 1 & 13.0 & 131.5 & 56.0 & 75.5 & 13.0 & 16030.2 & 16034.0 \\
\hline 2 & 40.0 & 486.8 & 248.0 & 338.8 & 40.0 & $39342.7^{\mathrm{c}}$ & $39320.0^{c}$ \\
\hline 3 & 307.0 & 3880.8 & 2040.0 & 1804.8 & 307.0 & n.d. ${ }^{d}$ & 418274.0 \\
\hline 4 & 15.0 & 337.8 & 248.0 & 89.8 & 15.0 & 31736.1 & 31776.0 \\
\hline
\end{tabular}

${ }^{a_{T}}$ The values are calculated subtracting the number of the hydrogens belonging to the PAMAM dendrimers to the hydrogens resonating between 3.1 and $2.7 \mathrm{ppm}$. ${ }^{b}$ The degree of grafting was determined dividing the calculated hydrogens belonging to the linker for 6 (the number of hydrogens of the linker resonating between 3.1 and $2.7 \mathrm{ppm}$ for the monomeric AG) and rounded to the nearest unit. ${ }^{c}$ It was not possible to detect the MW of the conjugate, but we detected the peak corresponding the MW of the 40 Neo-linker unit. ${ }^{d}$ The MW was not detected probably because the dendrimer does not vaporize.

two cell lines, namely, HeLa and COS-7 cells. The antimicrobial activity of the whole array of PAMAMs and PAMAM derivatives was evaluated as well.

Synthesis and Characterization of PAMAM G2-, G4-, G7-Neo and PAMAM G4-GNeo Conjugates. AGs are a class of polyaminosugar antibiotics that have been widely used as chemotherapeutic agents in the treatment of bacterial infections and, more recently, as antifungal agents. ${ }^{29-31}$ Because of their cationic-bearing moieties, AGs have already been used to build cationic amphiphils ${ }^{32-34}$ and polymers ${ }^{35-37}$ for gene delivery. In this context, we have previously developed dendrimeric PAMAM G4-AG conjugates and studied their effectiveness as gene-delivery systems in three different cell lines. ${ }^{27}$ Considering the high performances obtained with such vectors, especially those of PAMAM G4 tethered with Neo and Paro, we decided to investigate more in depth the influence of the PAMAM generation on the ultimate transfection efficiency of the resulting dendriplexes. Moreover, because it has been shown that the conversion of the primary amines of AGs into guanidino groups increases dramatically the ability of 


\section{A)}

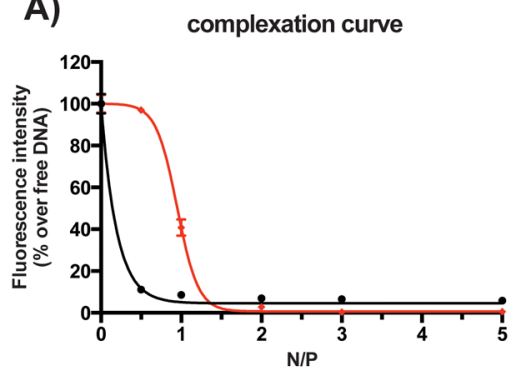

$\rightarrow$ PAMAMG2

B)
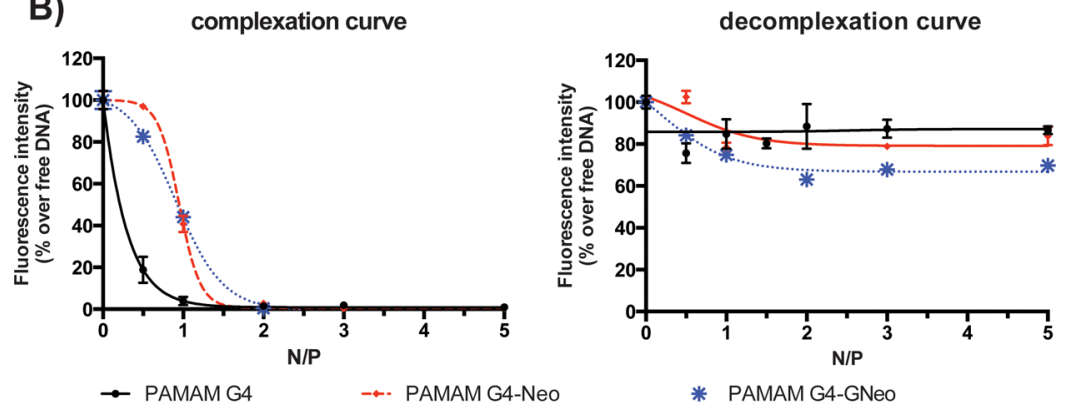

C)

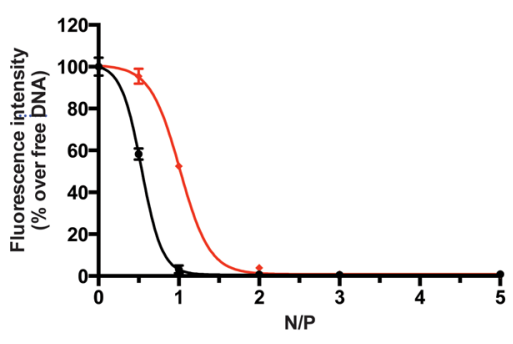

$\rightarrow$ PAMAMG7

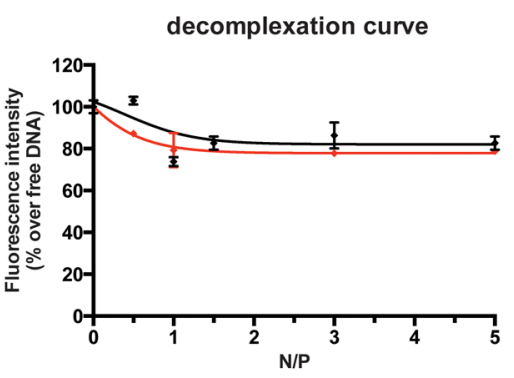

$\rightarrow$ PAMAM G2-Neo

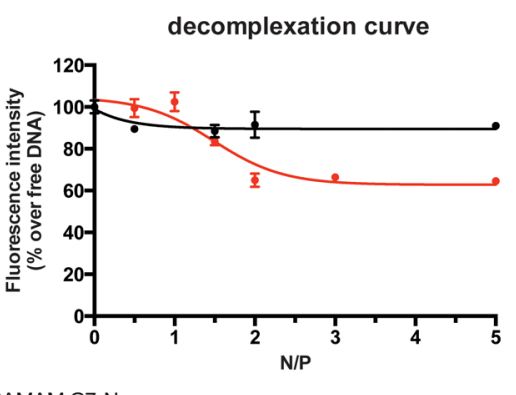

Figure 2. DNA complexation ability (left panels) and decomplexation ability (right panels) of PAMAM G2, G4, and G7 (black line) and their respective conjugates (red line or blue dotted line): (A) G2; (B) G4; (C) G7. Results are expressed as mean \pm SD $(n=3$ ).

guanidinoAGs to deliver high molecular weight cargos into cells, ${ }^{38-41}$ we decided to explore the effect of guanidinylation synthesizing a PAMAM G4-GNeo derivative. Likewise, we exploited the chemistry to anchor AGs and GNeo to the dendrimers, namely, click reaction between isothiocyanatefunctionalized AGs with the primary amino groups of the PAMAM dendrimers, while we slightly modified the linker in order to obtain the final conjugates in better yields and in a simpler way. In detail, starting from commercially available Neo 5, we have synthetized propargylic derivatives 6 and 7 following reported procedures (Scheme 1). ${ }^{42}$

Click reaction with isothiocyanate linker 8 (see Scheme S1 in the Supporting Information for the synthesis) led to the formation of intermediates 9 and 10, respectively, in good yields, which were next coupled with PAMAM G2, G4, and G7 following the same conditions (DMSO, $40{ }^{\circ} \mathrm{C}, 12 \mathrm{~h}$ ). After Boc-deprotection with trifluoroacetyl (TFA), dialysis in water, and freeze-drying, final PAMAM G2-Neo 1, PAMAM G4Neo 2, PAMAM G7-Neo 3, and PAMAM G4-GNeo 4 were obtained as fluffy solids.

According to our previous studies, ${ }^{27,38}$ the degree of grafting was first established by ${ }^{1} \mathrm{H}$ NMR analysis. Integration of the characteristic signals belonging to the Neo anomeric protons (three singlets resonating between 6.2 and $5.2 \mathrm{ppm}$ ), the protons belonging to the triazole ring (which resonates around $8.0 \mathrm{ppm}$ ), was compared to the integration of the broad multiplet resonating between 3.1 and $2.7 \mathrm{ppm}$ which correspond to (1) the methylene protons in the $\alpha$ position to the carbonyl group of PAMAM dendrimers ( 56 protons for PAMAM G2, 248 protons for PAMAM G4, and 2040 protons for PAMAM G7), (2) the two methylene groups in the $\alpha$ position to the sulfur atom and (3) the methylene in the $\alpha$ position to the carbonyl group, both belonging to the linker. The relative integrations of these signals revealed that we grafted 13 Neo to PAMAM G2, 40 Neo and 15 GNeo to PAMAM G4, and 307 Neo to PAMAM G7 (Table 1). The lower degree of grafting obtained with GNeo isothiocyanate 10 as compared to the corresponding Neo derivative $\mathbf{9}$ could be ascribed to the different steric hindrance. Besides PAMAM G7-Neo 3, the degrees of grafting of 1, 2, and 4 were also supported by MALDI mass analysis, through which the average molecular mass of the dendrimer derivatives was evaluated and compared to those calculated (Table 1).

Evaluation of DNA-Binding Ability and Release Behavior of PAMAM and PAMAM-(G)Neo Conjugates. The delivery of naked pDNA into cells is not efficient because of the enzymatic degradation (by DNases) of NAs and the charge repulsion with the plasma membrane. Thereby, safe and 
A)

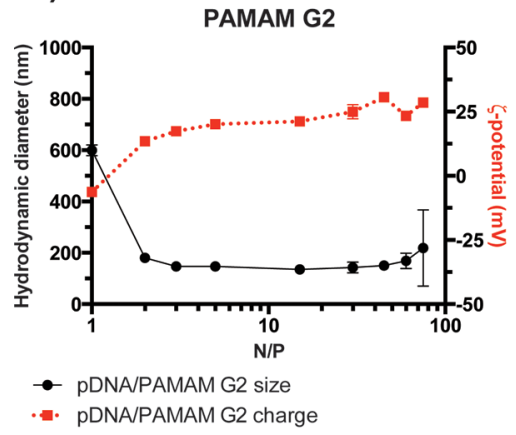

B)

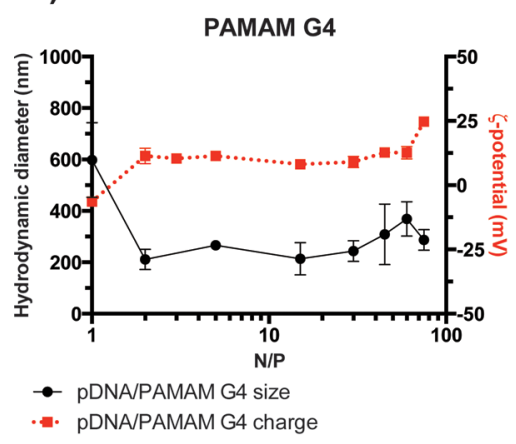

C)

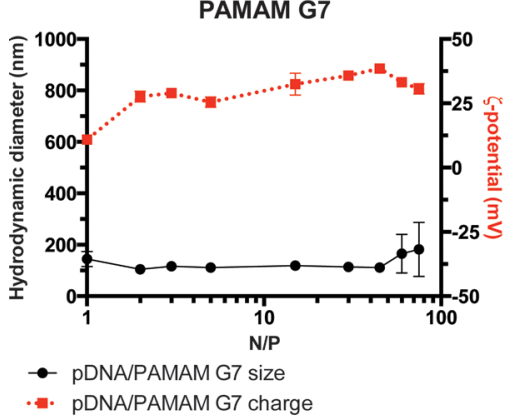

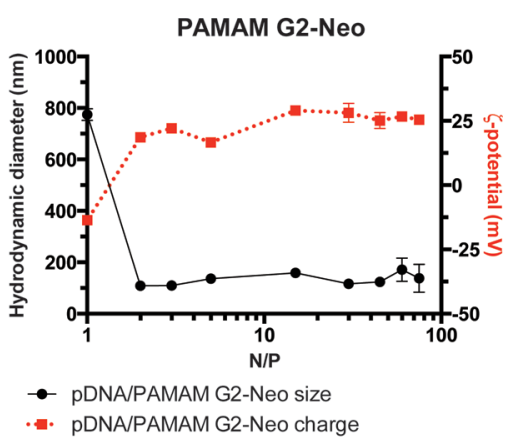

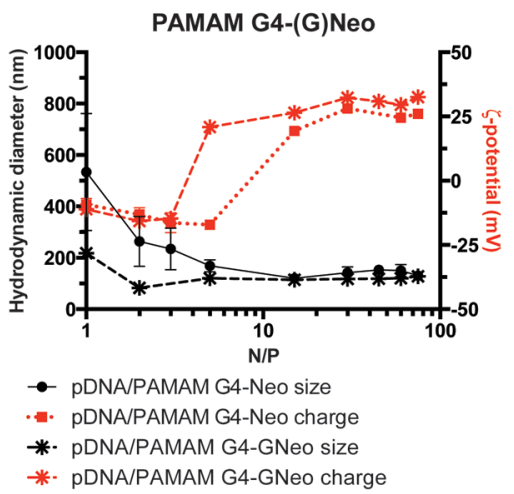

*- pDNA/PAMAM G4-GNeo charge

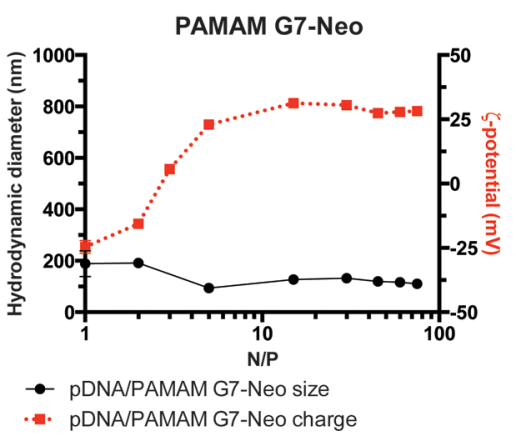

Figure 3. Physico-chemical characterization of pDNA/PAMAMs and pDNA/PAMAM-AG complexes. Mean hydrodynamic diameter $\left(D_{\mathrm{H}}\right.$; black circle (star) and solid (dashed) line) and overall surface charge $\left(\zeta_{\mathrm{p}}\right.$; red square (star) and dotted (dashed) line), measured by DLS and laser doppler microelectrophoresis, of: (A) pDNA/PAMAM G2 (left panel) and pDNA/PAMAM G2-Neo (right panel) complexes; (B) pDNA/ PAMAM G4 (left panel) and pDNA/PAMAM G4-(G)Neo (right panel) complexes; and (C) pDNA/PAMAM G7 (left panel) and pDNA/ PAMAM G7-Neo (right panel) complexes. Results are expressed as mean $\pm \mathrm{SD}(n=3)$.

efficient introduction of DNA/RNA into cells by means of synthetic vectors that do shield and protect the genetic cargo is of paramount importance for successful gene delivery. As for other polycations, such as polylysine and polyethylenimine (PEI), PAMAM dendrimers have been shown to self-assemble with NAs through electrostatic interactions to form dendriplexes. ${ }^{43}$ PAMAM dendrimers contains in their backbone both tertiary amines at branching points, as well as protonated primary amino groups at the termini, the latter being responsible for the binding of the pDNA phosphates. Besides, it has been found that Neo-tethering to dendrimers did enhance the ability of such polymers to pack the DNA. ${ }^{27}$

In this study, PAMAMs at different generations, that is, G2, G4, and G7, and their respective (G)Neo conjugates were used to complex and compact pDNA into polyplexes. We thus first evaluated by fluorophore-exclusion assay the ability of these three different arrays of gene-delivery vectors to bind and condense pDNA as a function of the nitrogen-to-phosphate ratio (N/P) (Figure 2, left panels). By plotting the fluorescence intensity versus $\mathrm{N} / \mathrm{P}$, all the dendrimers tested displayed typical quasi-sigmoidal curves (PAMAM G2 and G2-Neo: Figure 2A; PAMAM G4, G4-Neo and G4-GNeo: Figure 2B; and PAMAM G7 and G7-Neo: Figure 2C).

Overall, PAMAM derivatives invariably showed higher affinity for DNA than PEI, whose maximum pDNA complexation ability (i.e., when DNA is no longer accessible to the SYBR Green I because totally secluded in complexes) was found at $\mathrm{N} / \mathrm{P} \geq 3 .{ }^{44,45}$ Of note, PAMAM G2 did displace slightly less SYBR Green I, showing a residual fluorescence signal of $\approx 10 \%$ even at high $\mathrm{N} /$ Ps (Figure $2 \mathrm{~A}$ ). This behavior probably relies on the less tight binding of DNA owing to the little surface charge density of this low generation dendrimer. ${ }^{46-48}$ Interestingly, the presence of Neo increased the affinity of PAMAM G2 for pDNA, this AG being a well-known 
A)
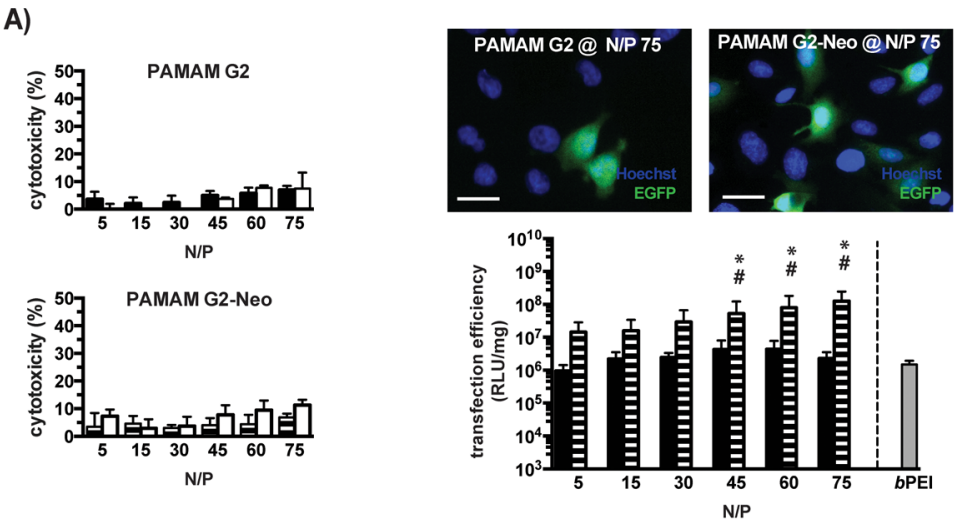

B)
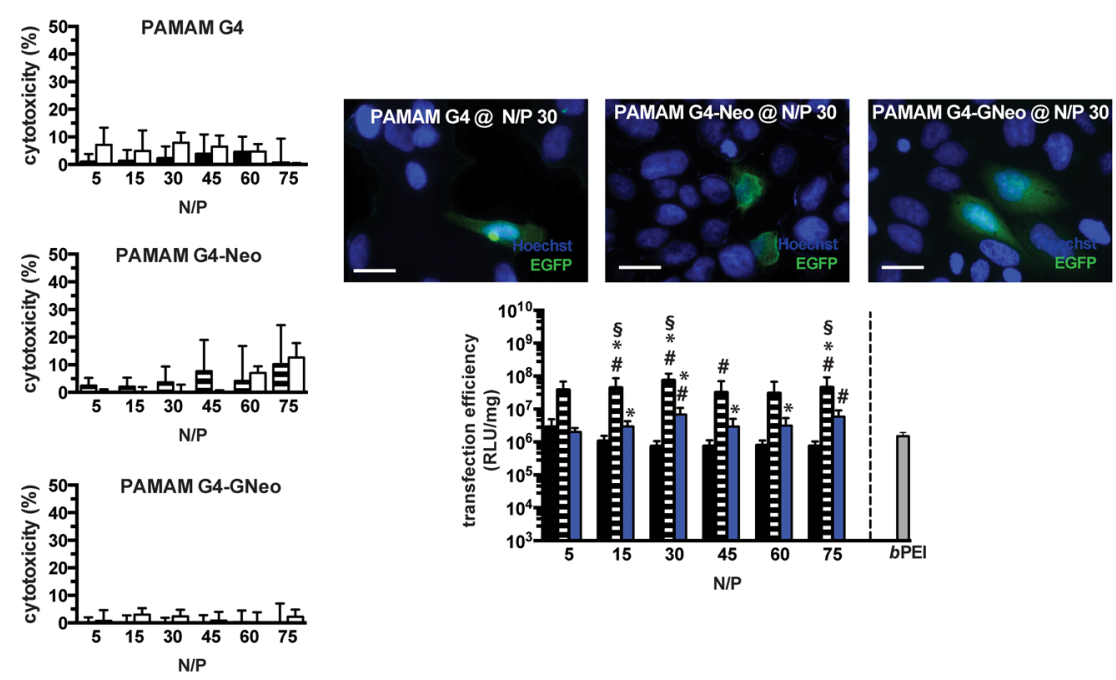

pDNAIPAMAM G2-Neo complexes

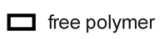

xes

- pDNA/PAMAM G4-Neo complexes $\square$ pDNA/PAMAM G4-GNeo complexes $\square$ free polymer

C)
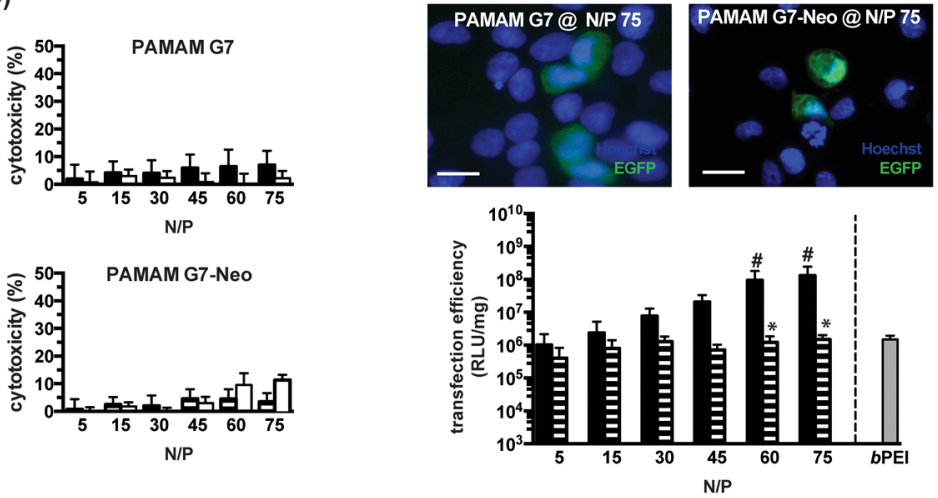

pDNAIPAMAM G7 complexes

pDNA/PAMAM G7-Neo complexes $\square$ free polymer

Figure 4. Cytotoxicity and transfection efficiency (EGFP expression and Luc activity) of PAMAM and PAMAM-(G)Neo-based complexes in HeLa cells, prepared by mixing pGL3 (or pEGFP) with PAMAMs at different N/Ps. Cytotoxicity of free polymers (without DNA) was evaluated as well. (A) PAMAM G2 and PAMAM G2-Neo; (B) PAMAM G4, PAMAM G4-Neo and PAMAM G4-GNeo; and (C) PAMAM G7 and PAMAM G7-Neo. pGL3/25 kDa $b$ PEI complexes at N/P 10 were used as the internal reference of transfection. Results are expressed as mean \pm SD $(n \geq 4)\left({ }^{*} p<0.05\right.$ vs unconjugated PAMAM; ${ }^{\S} p<0.05$ vs PAMAM G4-GNeo; ${ }^{*} p<0.05$ vs $b$ PEI). Scale bar in fluorescent micrographs: 10 $\mu \mathrm{m}$.

NAs binder. ${ }^{49}$ Indeed, PAMAM G2-Neo was able to completely condense pDNA at $\mathrm{N} / \mathrm{P} \geq 1.5$.

Besides, unconjugated PAMAM G4 and G7 displayed similar behaviors because the greatest DNA complexation efficiency was at N/P 1 . When tethering such PAMAMs with $\mathrm{Neo}$ or GNeo, a displacement of the complexation curve at high N/Ps was observed (maximum complexation ability at $\mathrm{N} /$ P 1.5 for PAMAM G4-Neo and N/P 2 for PAMAM G4GNeo and G7-Neo derivatives).

Parent PAMAMs showed different release behaviors with respect to their respective Neo conjugates (Figure 2, right panels). Indeed, in the presence of heparin, PAMAM G2-, G4-, 
and G7-based nanoassemblies at $1 \leq \mathrm{N} / \mathrm{P} \leq 5$ were prone to decomplexation, and $\approx 90 \%$ of total $\mathrm{pDNA}$ was released out. Under the same decomplexation conditions, PAMAM G2Neo and G4-Neo-based dendriplexes released less pDNA, as a result of the greater stability of such assemblies. Such stability can be a critical issue for gene-delivery vectors, especially in anionic environments such as those that transfectants have to face up to in vitro and in vivo (e.g., the presence of serum, plasma glycoproteins and glycolipids). On the other hand, the poorer DNA release behavior displayed by PAMAM G4GNeo and PAMAM G7-Neo means that their respective polyplexes are more stable, and such stability may have a detrimental effect on intracellular DNA release and thus on transfection. In light of this, in order to develop gene delivery as effective as possible, we need to find a balance between stability of complexes and ease of DNA release. ${ }^{50}$

Physico-chemical Characterization of PAMAM - and PAMAM-(G)Neo-Based Polyplexes. As PAMAM G2, G4, and G7 dendrimers display a well-defined three-dimensional structure and chemistry, such features allow preparing complexes with a consistent structure, size, and surface charge. ${ }^{48}$ Therefore, we investigated by dynamic light scattering (DLS) and electrophoretic light scattering the hydrodynamic diameter $\left(D_{\mathrm{H}}\right)$ and the zeta potential $\left(\zeta_{\mathrm{P}}\right)$ of every dendriplex in order to find a possible correlation between the physico-chemical properties of PAMAM and PAMAMNeo-based complexes and the transfection behaviors in vitro. In fact, it is well accepted that the size and surface charge are among the key factors affecting the transfection performances of any gene-delivery vector, at least in vitro. ${ }^{44,45}$

PAMAM G2, G4, and G7 dendrimers in association with pDNA did form nanometric assemblies at $\mathrm{N} / \mathrm{P} \geq 2$ (i.e., at the same $\mathrm{N} / \mathrm{P}$ in which the DNA is totally buried within dendriplexes), while the $D_{\mathrm{H}}$ profile of every PAMAM-Neo derivative was fairly constant at $\mathrm{N} / \mathrm{P} \geq 5$ (Figure 3 ). The $\zeta_{\mathrm{P}}$ curves of low generation PAMAMs and PAMAM-Neo derivatives as a function of $\mathrm{N} / \mathrm{P}$ fitted well with an exponential decay equation model, while the best curve fit for PAMAM G7 and G7-Neo was the linear least-squares line with slope 0 , so that we found only minor variations in the overall dimensions of dendriplexes as the $\mathrm{N} / \mathrm{P}$ was increased.

In more detail, complexes of PAMAM G2 and G7 and their corresponding - Neo conjugates, prepared at N/P $\geq 2$, showed similar dimensions, ranging over a narrow distribution of $\approx 100-170 \mathrm{~nm}$ (Figure 3A,C) ( $p>0.05$ for every series), along with highly positive $\zeta_{\mathrm{P}}$, in good agreement with previously published data. ${ }^{48}$ Among them, pDNA/PAMAM G7 complexes displayed the highest $\zeta_{\mathrm{P}}$ of $\approx+35 \mathrm{mV}$, while PAMAM G2-based dendriplexes exhibited an overall surface charge of $+20-25 \mathrm{mV}$. Such results substantiate the evidence that surface charge is related to dendrimer generation, with PAMAM G2 and G7 showing different $\zeta_{\mathrm{P}}$ behaviors, irrespective of the $\mathrm{N} / \mathrm{P}$.

On the other hand, PAMAM G4-based complexes (at N/P $\geq 2$ ) displayed the largest $D_{\mathrm{H}}$, ranging from 200 to $450 \mathrm{~nm}$ (Figure $3 \mathrm{~B}$ ), and the lowest $\zeta_{\mathrm{p}}$ of $\approx+10 \mathrm{mV}$, in agreement with previously published data. ${ }^{27,51}$ The conjugation with Neo, whether or not guanidinylated, gave rise to the formation of smaller complexes with $D_{\mathrm{H}}<200 \mathrm{~nm}$ (Figure 3B) and higher $\zeta_{\mathrm{P}}$ of $\approx+25 \mathrm{mV}$ (at $\mathrm{N} / \mathrm{P} \geq 5$ ). It is also apparent that no stable and fully condensed dendriplexes were found for PAMAM G2 and $\mathrm{G} 4$ series at $\mathrm{N} / \mathrm{P}<2$, as highlighted by high $D_{\mathrm{H}}$ values and the overall negative surface charge (Figure $3 \mathrm{~A}, \mathrm{~B}$ ). This was probably because in such conditions residual unshielded DNA was still present.

Taken together, these results led to the conclusion that all PAMAMs effectively condense pDNA into nanoassemblies with positive surface charge, although to a different extent. This is a compulsory requirement for gene-delivery vectors.

In Vitro Transfection of pDNA/PAMAMs and pDNA/ PAMAMs-(G)Neo Conjugates. Transfection efficiency mediated by PAMAM dendrimers has been shown to be dependent on the dendrimer generation. In fact, the higher the generation, the greater the efficiency. ${ }^{48,52}$

In two cell lines, namely, HeLa and COS-7 cells, dendriplexes obtained through the mixing of PAMAM G2 $(-\mathrm{Neo}), \mathrm{G} 4(-\mathrm{Neo})$, and G7 ( $-\mathrm{Neo})$ with pDNA at N/P $\geq 5$ exhibited transfection efficiencies (in terms of Luc activity) similar or even greater than the gold standard $25 \mathrm{kDa} b$ PEI. Of note, pristine PAMAMs displayed different, generation-specific transfection behaviors. As clearly shown in Figure 4, pDNA/ PAMAM G4 showed the lowest transfection efficiency, regardless of the N/P tested. Such outcome is not surprising if considering the lower $\zeta_{\mathrm{P}}$ displayed by PAMAM G4-based dendriplexes with respect to that of the other PAMAMs. On the other hand, pDNA/PAMAM G7 displayed the highest transfection efficiency at almost all N/Ps tested, with the greatest transgene expression at $\mathrm{N} / \mathrm{P} 75$ (Figure 4C, right panel) and a very low cytotoxicity (Figure 4C, left panel). Besides, the transfection efficiency of pDNA/PAMAM G2 dendriplexes showed a bell-shape trend, with the maximum centered at N/P 45 (Figure 4A, right panel). Our findings show that high generation dendrimers (PAMAM G7) were more effective in transfecting cells than the less branched counterparts (PAMAM G2 and G4). Similar results were reported by Kukowska-Latallo as well. ${ }^{52}$ Although to a different extent, such trends were also found transfecting COS-7 cells, both in terms of cytotoxicity (Figure S5, left panels) and Luc activity (Figure S5, right panels).

We have recently shown that the conjugation of PAMAM G4 with AGs, such as Neo, Paro, and neamine, dramatically enhanced the transfection behavior. ${ }^{27}$ In the present study, we made another step forward in putting the puzzle together through the investigation of the possible effects of grafting different generations of PAMAM dendrimers with the AG unit Neo.

Interestingly, PAMAM G2-Neo dendriplexes at any N/P tested displayed a $\approx 10$-fold increase in the Luc expression than the pristine PAMAM G2 one in both HeLa (Figure 4A, right panel) and COS-7 cells (Figure S5A, right panel). Instead, PAMAM G7-Neo displayed an opposite behavior. In fact, from Figure 4C (and Figure S5C), it is apparent that pDNA/ PAMAM G7-Neo dendriplexes induced lower luciferase expression in HeLa cells (and COS-7 as well) than pDNA/ PAMAM G7 complexes, especially for high N/Ps. It is worthy of note that the physico-chemical features of complexes prepared with PAMAM G2 and G7 (and the corresponding - AG conjugates) were quite different (PAMAM G2 $(-\mathrm{Neo})$ at N/P 5-75: $\zeta_{\mathrm{P}} \approx+25 \mathrm{mV}$ versus PAMAM G7 $(-\mathrm{Neo})$ at N/P 5-75: $\left.\zeta_{\mathrm{P}} \approx+35 \mathrm{mV}\right)$, which means that the differences found in transfection may rely on the PAMAM generation underpinning the specific features of pDNA/PAMAM assemblies. Yet, the poorer DNA release behavior displayed by PAMAM G7-Neo limited in some way their transfection efficiency.

Similar to PAMAM G2 series, pDNA/PAMAM G4-Neo dendriplexes were much more efficient in transfecting $\mathrm{HeLa}$ 


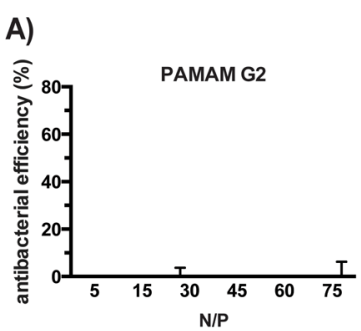

pDNA/PAMAM G2 complexes

B)

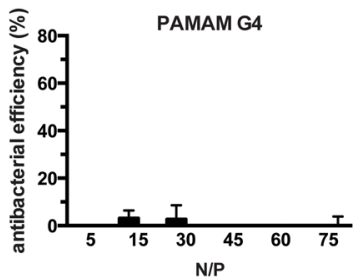

DDNA/PAMAM G4 complexes

C)

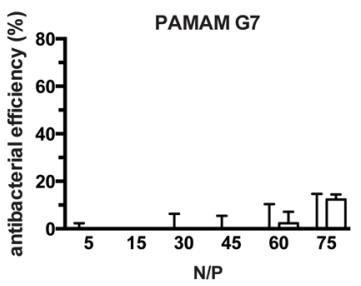

pDNA/PAMAM G7 complexes

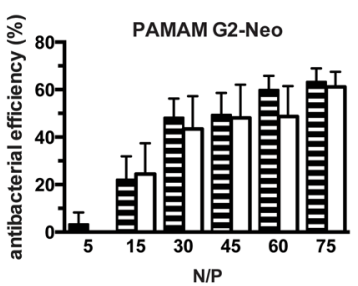

pDNA/PAMAM G2-Neo complexes
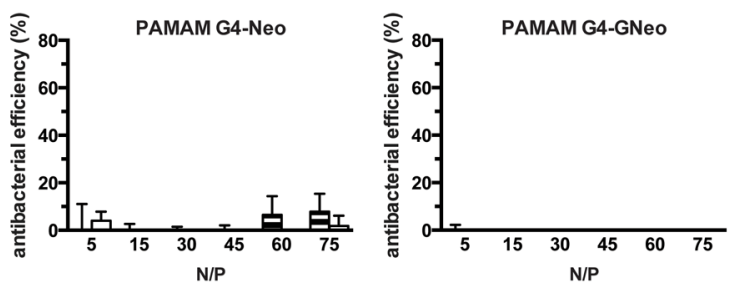

N/P

$\square$ pDNAIPAMAM G4-GNeo complexes $\square$ free polymer

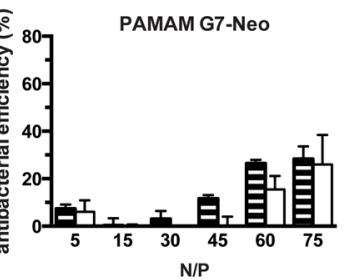

pDNA/PAMAM G7-Neo complexes $\square$ free polymer

Figure 5. Antibacterial activity of complexes and (DNA-free) polymer solutions of PAMAMs and their respective (G)Neo-conjugates against E. coli. (A) PAMAM G2 and PAMAM G2-Neo; (B) PAMAM G4 and PAMAM G4-(G)-Neo; (C) PAMAM G7 and PAMAM G7-Neo (right panels). Results are expressed as mean $\pm \mathrm{SD}(n=3)\left({ }^{*} p<0.05\right.$ complexes vs polymer solutions).

(Figure 4B) and COS-7 cells (Figure S5B) than complexes prepared with parent PAMAM G4. In particular, PAMAM G4-Neo was more effective at N/P 30 in both cell lines.

On the other hand, a similar trend was observed when GNeo was tethered to PAMAM G4. As reported in Figure 4B, the transfection efficiency of pDNA/PAMAM G4-GNeo complexes was higher than that of PAMAM G4 complexes prepared at N/P > 5, and the cytotoxicity they showed was low-to-negligible.

As expected, also the transfection profiles of such dendriplexes were strongly dependent on the $\mathrm{N} / \mathrm{P}$ and the cell line used to carry out transfections; when used to transfect HeLa and COS-7 cells, pDNA/PAMAM G4-GNeo complexes were indeed more effective at N/P 30 and N/P 75, respectively (Figure 4B, right panel, and S5B, right panel). Besides, pDNA/PAMAM G4-GNeo complexes were less efficient than the $-\mathrm{Neo}$ counterparts. Such findings mirrored the results reported by Lehn's group. ${ }^{53}$ The reasons for such unfavorable effect can be ascribed to the poorer DNA release ability shown by PAMAM G4-GNeo (Figure 3). It is widely accepted that the grafting of guanidino groups to macromolecules favors their cellular uptake. ${ }^{38,39,41}$ However, after polyplex uptake, the DNA decomplexation has to occur in a way as efficient as possible in order to enable the release of the transgene and thus its transcription. Our experimental evidence suggests that the presence of guanidinium moieties, in lieu of the primary amines, is likely to strengthen the interaction with the DNA, thus increasing excessively the stability of complexes so that cells are hardly able to disassemble them intracellularly. Besides, we may speculate that the strong basicity of the guanidino group may also affect the buffering capacity of the PAMAM dendrimers, which is one of the reasons of the high transfection activities of several cationic vectors such as PEI. ${ }^{54}$

In order to actually visualize transfection, EGFP-encoding complexes were delivered to HeLa cells at optimal N/P (PAMAM G2 and G2-Neo: N/P 75; PAMAM G4 and G4Neo: N/P 30; and PAMAM G7 and G7-Neo: N/P 75), as reported in Figure 4.

It is worth noting that every PAMAM- $(\mathrm{G})$ Neo dendrimer, when tested at the optimum $\mathrm{N} / \mathrm{P}$, invariably exhibited greater transfection efficiency than the gold standard $25 \mathrm{kDa} b P E I$ in both HeLa and COS-7 cells.

On the other hand, although a high cationic charge density allows polymers to associate with DNA and to give rise to nanoassemblies amenable to cellular internalization, the latter process is also known to adversely impact cell viability. As the overall cytotoxicity of a given non-viral gene-delivery vector depends on its inherent toxicity, which relies on the chemical structure and composition, and on the physico-chemical properties of the resulting polyplexes (i.e., their size $\left(D_{\mathrm{H}}\right)$ and surface charge $\left(\zeta_{\mathrm{P}}\right)$ ), we have challenged HeLa cells with polyplexes at different $\mathrm{N} / \mathrm{Ps}$ and free polymer solutions (prepared at the same polymer concentration used to complex pDNA at different N/Ps, but without DNA addition). For every $\mathrm{N} / \mathrm{P}$ tested, the cytotoxicity of polyplexes basically mirrored that of free polymers (Figures 4 and S5; $p>0.05$ for all the conditions), probably because at $\mathrm{N} / \mathrm{P} \geq 5$, most of the 
polymer is not engaged in interactions with pDNA (maximal complexation ability at $\mathrm{N} / \mathrm{P} \leq 2$ for all the PAMAMs). Most importantly, these results highlight the inherently low cytotoxicity of PAMAM- $(\mathrm{G}) \mathrm{Neo}$ conjugates.

Antibacterial Activity of pDNA/PAMAMs and pDNA/ PAMAMs-(G)Neo Conjugates. PAMAM dendrimers have been extensively investigated for biomedical applications, especially for delivery of drugs, including antimicrobial drugs, to mammalian cells. Although PAMAM and other dendrimers have been widely used as carriers or scaffolds for the covalent tethering of antimicrobial agents, such as antibiotics, ${ }^{55,56}$ the antimicrobial effectiveness of PAMAM dendrimers themselves has only been recently discovered. ${ }^{57}$ In this light, modification of the PAMAM's amino groups with Neo, a well-known and widely used antibiotic active against Gram-negative bacteria, ${ }^{58}$ may enhance the antibacterial performance of such dendrimers. We thus hypothesized that PAMAM G2, G4, and G7, whether or not conjugated with $\mathrm{Neo}$, might have antibacterial activity. We thus tested the potential antimicrobial activity against Gram negative Escherichia coli (E. coli) bacteria of PAMAM conjugated 1-4, used as aqueous (polymer) solutions and in the form of suspensions of $\mathrm{pDNA} /$ PAMAM-(G)Neo complexes and compared their performances to those of unconjugated dendrimers.

As clearly shown in Figure 5, unconjugated PAMAMs were ineffective against E. coli. Interestingly, the conjugation with Neo dramatically increased the antibacterial activities of dendrimers (Figure 5), especially when low generation PAMAM was used. Among the PAMAM-Neo derivatives, PAMAM G2-Neo was the most effective antibacterial compound, and its effects were concentration-dependent (Figure 5A, left panel).

The tethering of PAMAM G4 with the antibiotic Neo induced a mild increase in antibacterial activity, whereas the guanidylation of the AG's amino group totally blunted its activity (Figure 5B). Based on these findings, we can speculate that the antimicrobial effect of PAMAM conjugates specifically rely on the grafting of the pristine antibiotic moiety on the dendrimer.

Altogether, these results disclose PAMAM G2-Neo as a promising gene-delivery transfectant with good antibacterial properties.

\section{CONCLUSIONS}

Herein, we have synthesized and characterized a series of four different PAMAM-(G)Neo conjugates, namely, PAMAM G2-Neo, PAMAM G4-Neo, PAMAM G4-GNeo, and PAMAM G7-Neo. We evaluated their ability to condense DNA and to release it in the presence of a decomplexation agent. Moreover, their cytotoxicity and ability to transfect two cell lines were evaluated as well. Besides PAMAM G7-Neo, all the other conjugates showed greater transfection efficiencies as compared to their corresponding undecorated PAMAM dendrimers. The PAMAM G4-GNeo derivative was much less efficient than the corresponding Neo derivative although GNeo (and in general guanidinylation) is known to promote efficient cellular uptake. Of note, PAMAM G2-Neo was the most effective transfectant because very efficient (and much more efficient than gold standard transfectant $25 \mathrm{kDa} b \mathrm{PEI}$ ) at any N/P. Notably, small PAMAM G2-Neo were able to completely condense pDNA, which was not the case for the undecorated PAMAM G2, and, at high N/P (N/P $\geq 45)$, displayed low cytotoxicity and was more efficient in transfecting HeLa cells than PAMAM G4-Neo.

Benefiting from the grafting of AGs, PAMAM G2-Neo exhibited very good antibacterial activity against $E$. coli. These results are very intriguing because low generation dendrimers are cheaper, safer, and easier to functionalize as compared to the higher generation counterparts. Overall, this study highlights the beneficial effect on transfection of Neo-grafting on low- (G2) to medium- (G4) generation PAMAM dendrimers. Because of high transfection efficiency, low cytotoxicity, and low costs, PAMAM G2-Neo is a very promising gene-delivery vehicle.

\section{MATERIALS AND METHODS}

Materials. Neo sulfate, PAMAM G2, G4, and G7 dendrimers, and $25 \mathrm{kDa} b \mathrm{PEI}$ were from Sigma-Aldrich (Milan, Italy). Spectra/Por dialysis bags (MWCO $=1$ and 8 $\mathrm{kDa}$ ) were from Spectrum Laboratories (Compton, CA, USA).

HeLa (human cervix carcinoma, CCL-2) and COS-7 (monkey kidney tissue-derived fibroblast-like, CRL-1651) cell lines were purchased from the American Type Culture Collection (ATCC, Manassas, VA, USA). AlamarBlue Cell Viability Assay was from Life Technologies Italia (Monza, Italy), while the BCA Protein Assay Kit was from Thermo Fisher (Monza, Italy). pDNA encoding the modified firefly luciferase (pGL3-Control Vector, $5.2 \mathrm{kbp}$ ) and Luciferase Assay System were obtained from Promega (Milan, Italy), while pDNA encoding the enhanced green fluorescent protein (pEGFP-N1, $4733 \mathrm{bp}$ ) was purchased from Clontech Laboratories (Mountain View, CA).

E. coli JM109, (Gram negative bacterial strain, biosafety level: 1) were purchased from Leibniz Institute DSMZGerman Collection of Microorganisms and Cell Cultures (Braunschweig, Germany).

All the other chemicals were from Sigma-Aldrich, if not differently specified.

Synthesis of PAMAM-AG Conjugates 1-4: General Procedure. The organic solvent of commercial $10 \%(\mathrm{w} / \mathrm{w})$ methanolic solution of PAMAM of different generations was evaporated in vacuo and co-evaporated twice with dichloromethane. Neat PAMAM was dissolved in DMSO and a solution of the AG-isothiocyanate linker (1.2 equiv per $\mathrm{NH}_{2}$ group) in a minimal volume of DMSO was added. The solution was stirred at $60{ }^{\circ} \mathrm{C}$ for $24 \mathrm{~h}$. The solution was dialyzed against $\mathrm{MeOH}$ ( $8 \mathrm{~h}$, the solvent reservoir was renewed three times, $\mathrm{MWCO}=1$ and $8 \mathrm{kDa})$. The solution was evaporated under reduced pressure to give $\mathrm{N}$-Bocprotected PAMAM-AG derivatives. The resulting conjugates were dissolved in TFA and stirred for $30 \mathrm{~min}$ at room temperature (rt). The excess of TFA was evaporated under reduced pressure, the crude dissolved in demineralized water $\left(\mathrm{dH}_{2} \mathrm{O}\right)$, and the solution dialyzed overnight (ON) against $\mathrm{dH}_{2} \mathrm{O}(\mathrm{MWCO}=1 \mathrm{kDa})$. Freeze-drying of the resulting $\mathrm{dH}_{2} \mathrm{O}$ solution lead to recover fluffy, white solids. Complete $N$-Boc deprotection occurred in all cases as evidenced by the NMR spectra.

Preparation of Dendrimer Solutions. PAMAM G2, G4, and $\mathrm{G} 7$ were diluted in $\mathrm{dH}_{2} \mathrm{O}$ to a final concentration of 4.48 , 5.0 , and $5.0 \mathrm{mg} / \mathrm{mL}$, respectively, corresponding invariably to final nitrogen concentration $([\mathrm{N}])$ of $22 \mathrm{mM}$. PAMAM G2Neo, G4-Neo, and G4-GNeo derivatives were diluted in $\mathrm{dH}_{2} \mathrm{O}$ to a final concentration of $4.05,4.12$, and $4.57 \mathrm{mg} / \mathrm{mL}$, respectively, corresponding invariably to a final nitrogen 
concentration $([\mathrm{N}])$ of $13 \mathrm{mM}$. PAMAM G7-Neo was diluted in $\mathrm{dH}_{2} \mathrm{O}$ to a final concentration of $2.07 \mathrm{mg} / \mathrm{mL}$, corresponding to final $[\mathrm{N}]$ of $6.5 \mathrm{mM}$, while $25 \mathrm{kDa} b \mathrm{PEI}$ was diluted in $10 \mathrm{mM}$ HEPES to a final concentration of $0.86 \mathrm{mg} /$ $\mathrm{mL}$ and $\mathrm{a}[\mathrm{N}]=20 \mathrm{mM}$, considering that there is one nitrogen per repeat PEI unit $\left(-\mathrm{NHCH}_{2} \mathrm{CH}_{2}-, \mathrm{MW}=43 \mathrm{Da}\right) .{ }^{59}$ Dendrimers and $b$ PEI were stored at $4{ }^{\circ} \mathrm{C}$ until use.

Preparation of Polyplexes and Evaluation of DNA Binding and Release Ability. The DNA binding and release ability of every PAMAM and PAMAM-Neo conjugates were monitored by fluorophore-displacement assay. First, pDNA was amplified, isolated, purified, and diluted in $0.1 \times \mathrm{TE}$ buffer (1 mM Tris, $\mathrm{pH} 8 ; 0.1 \mathrm{mM}$ EDTA) as previously described. ${ }^{60}$ Dendriplexes were invariably prepared by mixing $0.25 \mu \mathrm{g}$ of pDNA in $1.0 \mu \mathrm{L}$ of $200 \times$ SYBR Green I $\left(\lambda_{\mathrm{ex}}=497 \mathrm{~nm}, \lambda_{\mathrm{em}}=\right.$ $520 \mathrm{~nm}$ ) with $11.8 \mu \mathrm{L}$ of PAMAMs and PAMAMs-Neo solutions at different concentrations, yielding a final DNA concentration of $20 \mathrm{ng} / \mu \mathrm{L}$ and different N/Ps. N/P is defined as the moles of amines ( $\mathrm{N}$, cationic moiety) of the dendrimer and Neo, when applicable, which are used to complex the phosphate groups (P, anionic moiety) of a given quantity of DNA. Afterward, polyplexes were incubated for $30 \mathrm{~min}$ at $\mathrm{rt}$, then diluted 1:16 (v/v) in $10 \mathrm{mM}$ HEPES or $200 \mu \mathrm{g} / \mathrm{mL}$ of 10 $\mathrm{mM}$ HEPES-containing heparin. Fluorescence measurements ( $n=3$ per condition) were performed with a GENios Plus Reader (Tecan, Segrate, Italy) in 384-well black plates. Data are expressed as relative fluorescence normalized to the fluorescence of uncomplexed pDNA.

Measurement of the Size $\left(D_{H}\right)$ and Zeta-Potential $\left(\zeta_{\mathrm{P}}\right)$ of Complexes. For physico-chemical characterization, complexes were prepared as described above. Briefly, $1 \mu \mathrm{g}$ of pDNA was mixed with PAMAMs and PAMAMs-Neo solutions to yield different N/Ps (i.e., 5, 15, 30, 45, 60, and 75 ), incubated for $30 \mathrm{~min}$ at rt then diluted $1: 15$ in $10 \mathrm{mM}$ HEPES. The hydrodynamic diameter $\left(D_{\mathrm{H}}\right)$ and surface charge $\left(\zeta_{\mathrm{P}}\right)$ of dendriplexes were measured at $37^{\circ} \mathrm{C}$ by DLS and laser Doppler micro-electrophoresis using a Malvern Zetasizer Nano instrument (Malvern, Italy), fitted with a $5 \mathrm{mV} \mathrm{HeNe}$ laser $(\lambda$ $=633 \mathrm{~nm}$ ) and a scattering angle of $173^{\circ}$.

In Vitro Cells Transfection Experiments. Cell Cultures. Mycoplasma-free HeLa and COS-7 cells were cultured in Dulbecco's modified Eagle's medium containing $1 \mathrm{mM}$ sodium pyruvate, $10 \mathrm{mM}$ HEPES buffer, $100 \mathrm{U} / \mathrm{mL}$ penicillin, $0.1 \mathrm{mg} /$ $\mathrm{mL}$ streptomycin, $2 \mathrm{mM}$ glutamine, and supplemented with $10 \%(\mathrm{v} / \mathrm{v})$ fetal bovine serum (i.e., culture medium) in a humidified atmosphere under a constant supply of $5 \% \mathrm{CO}_{2}$ and at $37{ }^{\circ} \mathrm{C}$.

In Vitro Cell Transfection. Cells were seeded onto 96-well plates at a density of $2 \times 10^{4}$ cells $/ \mathrm{cm}^{2}$ and maintained in standard culture conditions for $24 \mathrm{~h}$. Next, $160 \mathrm{ng} /$ well of pGL3 were complexed in $10 \mathrm{mM}$ HEPES with PAMAMs and PAMAMs-Neo solutions to yield different N/Ps, as described herein above, and cells were incubated with complexes in 100 $\mu \mathrm{L} /$ well of culture medium under standard culture conditions for further $48 \mathrm{~h}$. Cells transfected with $25 \mathrm{kDa} b \mathrm{PEI} / \mathrm{DNA}$ complexes prepared at $\mathrm{N} / \mathrm{P} 10$ were used as internal refs. ${ }^{34,44,45}$

Following $48 \mathrm{~h}$ transfection, cytotoxicity was evaluated by means of AlamarBlue assay according to manufacturer's instructions. Briefly, medium was removed and each well was loaded with $100 \mu \mathrm{L}$ of culture medium containing $1 \times$ resazurin dye. Cells were next incubated in standard culture conditions for $2 \mathrm{~h}$, and then the fluorescence of the medium was read with a GENios Plus reader $\left(\lambda_{\mathrm{ex}}=540 \mathrm{~nm} ; \lambda_{\mathrm{em}}=595 \mathrm{~nm}\right)$. Viability of untransfected cells (CTRL) was assigned to $100 \%$ and cytotoxicity was calculated as follows

$$
\text { Cytotoxicity [\%] = 100\% - viability [\%] }
$$

Cytotoxicity of free polymers (PAMAM solutions tested at the same concentrations used to complex pDNA) was evaluated as well.

Transfection efficiency was evaluated measuring the luciferase activity by means of the Luciferase Assay System, according to manufacturer's instructions. Briefly, cells were washed with phosphate buffered saline (PBS) and lysed with $110 \mu \mathrm{L} /$ well of the Cell Culture Lysis Reagent (Promega, Italy). Following a freeze-thawing cycle, $20 \mu \mathrm{L}$ of cell lysates were added to $50 \mu \mathrm{L}$ of the Luciferase Assay Reagent, and luminescence was measured by means of a GENios Plus reader. The luminescence signal (expressed as relative light units, RLU) of each sample was normalized to its protein content determined by BCA assay. Transfection efficiencies were thus expressed as RLU/mg of proteins.

To qualitatively assess transfection, HeLa cells were plated at the same cell density as reported herein above onto glass coverslips $(\varnothing=15 \mathrm{~mm})$, placed into separate wells of 24-well culture plates, and maintained in standard culture conditions for $24 \mathrm{~h}$. Afterward, $160 \mathrm{ng} / \mathrm{cm}^{2}$ of pEGFP was complexed with PAMAM - and PAMAM-(G)Neo solutions to give the most effective N/Ps as for pGL3, and cells were incubated for additional $48 \mathrm{~h}$ in standard culture conditions. At the end of transfection, cells were rinsed with PBS, fixed in $4 \%(\mathrm{w} / \mathrm{v})$ paraformaldehyde solution for $20 \mathrm{~min}$, and permeabilized for $30 \mathrm{~min}$ at RT with $0.01 \%(\mathrm{w} / \mathrm{v})$ Triton X, 3\% (w/v) BSA in PBS. Next, cell nuclei were counterstained with Hoechst 33342 at a 1:1000 dilution $(\mathrm{v} / \mathrm{v})$ in PBS plus $3 \%(\mathrm{w} / \mathrm{v})$ BSA. Coverslips were subsequently mounted on glass slides and digital images were taken with a Zeiss Axioplan fluorescent microscope at $40 \times$ magnification.

Antibacterial Tests. The antibacterial effectiveness of PAMAM G2, G4, G7, and their corresponding (G)Neo derivatives were tested against Gram negative E. coli JM109 bacterial strain, as previously described. ${ }^{34}$ Briefly, bacteria were cultured in $5 \mathrm{~mL}$ of Luria-Bertani (LB) broth at $37{ }^{\circ} \mathrm{C}$ under shaking at $130 \mathrm{rpm}, \mathrm{ON}$, until reaching an optical density at $\lambda$ $=600 \mathrm{~nm}\left(\mathrm{OD}_{600 \mathrm{~nm}}\right) \approx 1$, corresponding to $\approx 10^{9}$ bacteria $/ \mathrm{mL}$. Bacterial suspensions were next diluted to a final concentration of $\approx 10^{6}$ bacteria $/ \mathrm{mL}$ used as the test inoculum for the experiments. For antibacterial tests, $50 \mu \mathrm{L} /$ well of bacterial suspension was inoculated into separate wells of 96 -well plates (corresponding to a bacterial density of $1.5 \times 10^{5}$ bacteria/ $\mathrm{cm}^{2}$ ), then $50 \mu \mathrm{L} /$ well of LB containing pDNA/PAMAMs complexes prepared at varying $\mathrm{N} / \mathrm{P}$ or (uncomplexed, DNAfree) PAMAMs solutions prepared at the same polymer concentration used to complex pDNA were added. Plates were next incubated at $37^{\circ} \mathrm{C}$ for $24 \mathrm{~h}$. Bacteria inoculated in $50 \mu \mathrm{L} /$ well of $\mathrm{LB}$ were used as positive controls $\left(\mathrm{CTRL}^{+}\right)$for bacterial growth. The antibacterial efficacy of every compound was evaluated by means of the turbidity method (i.e., $\mathrm{OD}_{600 \mathrm{~nm}}$ measurements). ${ }^{36,61,62}$ Briefly, $24 \mathrm{~h}$ post inoculum, the $\mathrm{OD}_{600 \mathrm{~nm}}$ of each well $(n=3$ per compound) was read by means of a GENios Plus reader. The antibacterial efficiency was calculated according to the following equation 
Antibacterial efficiency [\%]

$$
=\left[1-\left(\mathrm{OD}_{600 \mathrm{~nm}, \text { compound }} / \mathrm{OD}_{600 \mathrm{~nm}, \mathrm{CTRL}^{+}}\right)\right] \times 100
$$

Statistical Analysis. Statistical analysis was carried out by GraphPad version 6 (GraphPad software, La Jolla, CA, USA). All data were initially analyzed using the D'Agostino \& Pearson omnibus normality test. Comparisons among groups were performed by the multiple $t$-test. Significance was retained when $p<0.05$. Data are expressed as mean \pm standard deviation (SD). Experiments were performed at least in triplicate.

\section{ASSOCIATED CONTENT}

\section{(5) Supporting Information}

The Supporting Information is available free of charge on the ACS Publications website at DOI: 10.1021/acsomega.8b02757.

Experimental procedure and characterization of linker 8, copies of the ${ }^{1} \mathrm{H}$ and ${ }^{1}$ MALDI spectra for all dendrimers, and cytotoxicity and transfection efficiencies of complexes evaluated in COS-7 cells (PDF)

\section{AUTHOR INFORMATION}

\section{Corresponding Authors}

*E-mail: gabriele.candiani@polimi.it (G.C.).

*E-mail: alessandro.volonterio@polimi.it. Phone: +39-0223993139. Fax: +39-02-23993180 (A.V.).

\section{ORCID}

Nina Bono: 0000-0002-6891-9879

Gabriele Candiani: 0000-0003-0575-068X

Alessandro Volonterio: 0000-0002-0125-0744

\section{Author Contributions}

${ }^{\perp}$ N.B. and C.P. equally contributed to the presented work.

Notes

The authors declare no competing financial interest.

\section{ACKNOWLEDGMENTS}

This work was supported by the Politecnico di Milano.

\section{REFERENCES}

(1) Tomalia, D. A. Birth of a new macromolecular architecture: dendrimers as quantized building blocks for nanoscale synthetic polymer chemistry. Prog. Polym. Sci. 2005, 30, 294-324.

(2) Medina, S. H.; El-Sayed, M. E. H. Dendrimers as Carriers for Delivery of Chemotherapeutic Agents. Chem. Rev. 2009, 109, 31413157.

(3) Tomalia, D. A. An architectural journey: from trees, dendrons/ dendrimers to nanomedicine. Nanomedicine 2012, 7, 953-956.

(4) Tomalia, D. A. Dendritic effects: dependency of dendritic nanoperiodic property patterns on critical nanoscale design parameters (CNDPs). New J. Chem. 2012, 36, 264-281.

(5) Tomalia, D. A. Dendrons/dendrimers: quantized, nano-element like building blocks for soft-soft and soft-hard nano-compound synthesis. Soft Matter 2010, 6, 456-474.

(6) García-Gallego, S.; Franci, G.; Falanga, A.; Gómez, R.; Folliero, V.; Galdiero, S.; de la Mata, F.; Galdiero, M. Function Oriented Molecular Design: Dendrimers as Novel Antimicrobials. Molecules 2017, 22, 1581.

(7) Scorciapino, M.; Serra, I.; Manzo, G.; Rinaldi, A. Antimicrobial Dendrimeric Peptides: Structure, Activity and New Therapeutic Applications. Int. J. Mol. Sci. 2017, 18, 542.
(8) Mintzer, M. A.; Dane, E. L.; O’Toole, G. A.; Grinstaff, M. W. Exploiting Dendrimer Multivalency To Combat Emerging and ReEmerging Infectious Diseases. Mol. Pharmaceutics 2012, 9, 342-354.

(9) Hsu, H.-J.; Bugno, J.; Lee, S.-r.; Hong, S. Dendrimer-based nanocarriers: a versatile platform for drug delivery. Wiley Interdiscip. Rev.: Nanomed. Nanobiotechnol. 2017, 9, No. e1409.

(10) Wang, H.; Huang, Q.; Chang, H.; Xiao, J.; Cheng, Y. Stimuliresponsive dendrimers in drug delivery. Biomater. Sci. 2016, 4, 375390

(11) Kesharwani, P.; Jain, K.; Jain, N. K. Dendrimer as nanocarrier for drug delivery. Prog. Polym. Sci. 2014, 39, 268-307.

(12) Nanjwade, B. K.; Bechra, H. M.; Derkar, G. K.; Manvi, F. V.; Nanjwade, V. K. Dendrimers: Emerging polymers for drug-delivery systems. Eur. J. Pharm. Sci. 2009, 38, 185-196.

(13) Svenson, S. Dendrimers as versatile platform in drug delivery applications. Eur. J. Pharm. Biopharm. 2009, 71, 445-462.

(14) Wolinsky, J.; Grinstaff, M. Therapeutic and diagnostic applications of dendrimers for cancer treatment $\boldsymbol{r}^{2}$. Adv. Drug Deliv. Rev. 2008, 60, 1037-1055.

(15) Krause, W.; Hackmann-Schlichter, N.; Maier, F. K.; Müller, R. Dendrimers in diagnostics. Dendrimers II 2000, 210, 261-308.

(16) Leiro, V.; Garcia, J. P.; Tomás, H.; Pêgo, A. P. The Present and the Future of Degradable Dendrimers and Derivatives in Theranostics. Bioconjugate Chem. 2015, 26, 1182-1197.

(17) Yang, J.; Zhang, Q.; Chang, H.; Cheng, Y. Surface-Engineered Dendrimers in Gene Delivery. Chem. Rev. 2015, 115, 5274-5300.

(18) Cheng, Y.; Zhao, L.; Li, Y.; Xu, T. Design of biocompatible dendrimers for cancer diagnosis and therapy: current status and future perspectives. Chem. Soc. Rev. 2011, 40, 2673-2703.

(19) Kang, H.; DeLong, R.; Fisher, M. H.; Juliano, R. L. Tatconjugated PAMAM dendrimers as delivery agents for antisense and siRNA oligonucleotides. Pharm. Res. 2005, 22, 2099-2106.

(20) Cao, Y.; Liu, X.; Peng, L. Molecular engineering of dendrimer nanovectors for siRNA delivery and gene silencing. Front. Chem. Sci. Eng. 2017, 11, 663-675.

(21) Duncan, R.; Izzo, L. Dendrimer biocompatibility and toxicity. Adv. Drug Deliv. Rev. 2005, 57, 2215-2237.

(22) Wang, M.; Liu, H.; Li, L.; Cheng, Y. A fluorinated dendrimer achieves excellent gene transfection efficacy at extremely low nitrogen to phosphorus ratios. Nat. Commun. 2014, 5, 3053.

(23) Cheng, Y. Fluorinated polymers in gene delivery. Acta Polym. Sin. 2017, 8, 1234-1245.

(24) Liu, H.; Wang, H.; Yang, W.; Cheng, Y. Disulfide cross-linked low generation dendrimers with high gene transfection efficacy, low cytotoxicity, and low cost. J. Am. Chem. Soc. 2012, 134, 17680-17687.

(25) Wang, H.; Wang, Y.; Wang, Y.; Hu, J.; Li, T.; Liu, H.; Zhang, Q.; Cheng, Y. Self-Assembled Fluorodendrimers Combine the Features of Lipid and Polymeric Vectors in Gene Delivery. Angew. Chem., Int. Ed. Engl. 2015, 54, 11647-11651.

(26) Xu, C.-T.; Chen, G.; Nie, X.; Wang, L.-H.; Ding, S.-G.; You, Y.Z. Low generation PAMAM-based nanomicelles as ROS-responsive gene vectors with enhanced transfection efficacy and reduced cytotoxicity in vitro. New J. Chem. 2017, 41, 3273-3279.

(27) Ghilardi, A.; Pezzoli, D.; Bellucci, M. C.; Malloggi, C.; Negri, A.; Sganappa, A.; Tedeschi, G.; Candiani, G.; Volonterio, A. Synthesis of multifunctional PAMAM-aminoglycoside conjugates with enhanced transfection efficiency. Bioconjugate Chem. 2013, 24, 19281936.

(28) Haensler, J.; Szoka, F. C., Jr. Polyamidoamine cascade polymers mediate efficient transfection of cells in culture. Bioconjugate Chem. 1993, 4, 372-379.

(29) Hermann, T.; Tor, Y. RNA as a target for small-molecule therapeutics. Expert Opin. Ther. Pat. 2005, 15, 49-62.

(30) Houghton, J. L.; Green, K. D.; Chen, W.; Garneau-Tsodikova, $\mathrm{S}$. The future of aminoglycosides: the end or renaissance? ChemBioChem 2010, 11, 880-902.

(31) Fosso, M. Y.; Li, Y.; Garneau-Tsodikova, S. New trends in the use of aminoglycosides. MedChem Comm 2014, 5, 1075-1091. 
(32) Desigaux, L.; Sainlos, M.; Lambert, O.; Chevre, R.; LetrouBonneval, E.; Vigneron, J.-P.; Lehn, P.; Lehn, J.-M.; Pitard, B. Selfassembled lamellar complexes of siRNA with lipidic aminoglycoside derivatives promote efficient siRNA delivery and interference. Proc. Natl. Acad. Sci. U.S.A. 2007, 104, 16534-16539.

(33) Mével, M.; Sainlos, M.; Chatin, B.; Oudrhiri, N.; Hauchecorne, M.; Lambert, O.; Vigneron, J.-P.; Lehn, P.; Pitard, B.; Lehn, J.-M. Paromomycin and neomycin B derived cationic lipids: synthesis and transfection studies. J. Controlled Release 2012, 158, 461-469.

(34) Bono, N.; Pennetta, C.; Sganappa, A.; Giupponi, E.; Sansone, F.; Volonterio, A.; Candiani, G. Design and synthesis of biologically active cationic amphiphiles built on the calix[4]arene scaffold. Int. J. Pharm. 2018, 549, 436-445.

(35) Lee, M. M.; French, J. M.; Disney, M. D. Influencing uptake and localization of aminoglycoside-functionalized peptoids. Mol. BioSyst. 2011, 7, 2441-2451.

(36) Chen, M.; Hu, M.; Wang, D.; Wang, G.; Zhu, X.; Yan, D.; Sun, J. Multifunctional hyperbranched glycoconjugated polymers based on natural aminoglycosides. Bioconjugate Chem. 2012, 23, 1189-1199.

(37) Miryala, B.; Feng, Y.; Omer, A.; Potta, T.; Rege, K. Quaternization enhances the transgene expression efficacy of aminoglycoside-derived polymers. Int. J. Pharm. 2015, 489, 18-29.

(38) Luedtke, N. W.; Carmichael, P.; Tor, Y. Cellular uptake of aminoglycosides, guanidinoglycosides, and poly-arginine. J. Am. Chem. Soc. 2003, 125, 12374-12375.

(39) Elson-Schwab, L.; Garner, O. B.; Schuksz, M.; Crawford, B. E.; Esko, J. D.; Tor, Y. Guanidinylated neomycin delivers large, bioactive cargo into cells through a heparan sulfate-dependent pathway. J. Biol. Chem. 2007, 282, 13585-13591.

(40) Sarrazin, S.; Wilson, B.; Sly, W. S.; Tor, Y.; Esko, J. D. Guanidinylated Neomycin Mediates Heparan Sulfate-dependent Transport of Active Enzymes to Lysosomes. Mol. Ther. 2010, 18, $1268-1274$.

(41) Sganappa, A.; Wexselblatt, E.; Bellucci, M. C.; Esko, J. D.; Tedeschi, G.; Tor, Y.; Volonterio, A. Dendrimeric Guanidinoneomycin for Cellular Delivery of Bio-macromolecules. ChemBioChem 2017, $18,119-125$.

(42) Dix, A. V.; Fischer, L.; Sarrazin, S.; Redgate, C. P. H.; Esko, J. D.; Tor, Y. Cooperative, heparan sulfate-dependent cellular uptake of dimeric guanidinoglycosides. ChemBioChem 2010, 11, 2302-2310.

(43) Kesharwani, P.; Banerjee, S.; Gupta, U.; Mohd Amin, M. C. I.; Padhye, S.; Sarkar, F. H.; Iyer, A. K. PAMAM dendrimers as promising nanocarriers for RNAi therapeutics. Mater. Today 2015, 18, $565-572$.

(44) Mintzer, M. A.; Simanek, E. E. Non-viral vectors for gene delivery. Chem. Rev. 2009, 109, 259-302.

(45) van Gaal, E. V. B.; van Eijk, R.; Oosting, R. S.; Kok, R. J.; Hennink, W. E.; Crommelin, D. J. A.; Mastrobattista, E. How to screen non-viral gene delivery systems in vitro? J. Controlled Release 2011, 154, 218-232.

(46) Navarro, G.; Tros de Ilarduya, C. Activated and non-activated PAMAM dendrimers for gene delivery in vitro and in vivo. Nanomedicine 2009, 5, 287-297.

(47) Chen, W.; Turro, N. J.; Tomalia, D. A. Using Ethidium Bromide To Probe the Interactions between DNA and Dendrimers $\dagger$. Langmuir 2000, 16, 15-19.

(48) Braun, C. S.; Vetro, J. A.; Tomalia, D. A.; Koe, G. S.; Koe, J. G.; Russell Middaugh, C. Structure/function relationships of polyamidoamine/DNA dendrimers as gene delivery vehicles. J. Pharm. Sci. 2005, 94, 423-436.

(49) Arya, D. P. New approaches toward recognition of nucleic acid triple helices. Acc. Chem. Res. 2011, 44, 134-146.

(50) Grigsby, C. L.; Leong, K. W. Balancing protection and release of DNA: tools to address a bottleneck of non-viral gene delivery. J. $R$. Soc., Interface 2010, 7, S67-S82.

(51) Yu, G. S.; Bae, Y. M.; Choi, H.; Kong, B.; Choi, I. S.; Choi, J. S. Synthesis of PAMAM dendrimer derivatives with enhanced buffering capacity and remarkable gene transfection efficiency. Bioconjugate Chem. 2011, 22, 1046-1055.
(52) Kukowska-Latallo, J. F.; Bielinska, A. U.; Johnson, J.; Spindler, R.; Tomalia, D. A.; Baker, J. R. Efficient transfer of genetic material into mammalian cells using Starburst polyamidoamine dendrimers. Proc. Natl. Acad. Sci. U.S.A. 1996, 93, 4897-4902.

(53) Sainlos, M.; Hauchecorne, M.; Oudrhiri, N.; Zertal-Zidani, S.; Aissaoui, A.; Vigneron, J.-P.; Lehn, J.-M.; Lehn, P. Kanamycin Aderived cationic lipids as vectors for gene transfection. ChemBioChem 2005, 6, 1023-1033.

(54) Vermeulen, L. M. P.; De Smedt, S. C.; Remaut, K.; Braeckmans, K. The proton sponge hypothesis: Fable or fact? Eur. J. Pharm. Biopharm. 2018, 129, 184-190.

(55) Yang, H.; Lopina, S. T. Penicillin V-conjugated PEG-PAMAM star polymers. J. Biomater. Sci., Polym. Ed. 2003, 14, 1043-1056.

(56) Cheng, Y.; Qu, H.; Ma, M.; Xu, Z.; Xu, P.; Fang, Y.; Xu, T. Polyamidoamine (PAMAM) dendrimers as biocompatible carriers of quinolone antimicrobials: an in vitro study. Eur. J. Med. Chem. 2007, $42,1032-1038$.

(57) Calabretta, M. K.; Kumar, A.; McDermott, A. M.; Cai, C. Antibacterial activities of poly(amidoamine) dendrimers terminated with amino and poly(ethylene glycol) groups. Biomacromolecules 2007, 8, 1807-1811.

(58) Dworkin, R. J. Aminoglycosides for the treatment of gramnegative infections: therapeutic use, resistance and future outlook. Drug Resist. Updates 1999, 2, 173-179.

(59) Zhang, C.; Yadava, P.; Hughes, J. Polyethylenimine strategies for plasmid delivery to brain-derived cells. Methods 2004, 33, 144150.

(60) Malloggi, C.; Pezzoli, D.; Magagnin, L.; De Nardo, L.; Mantovani, D.; Tallarita, E.; Candiani, G. Comparative evaluation and optimization of off-the-shelf cationic polymers for gene delivery purposes. Polym. Chem. 2015, 6, 6325-6339.

(61) Huang, Y.; Ding, X.; Qi, Y.; Yu, B.; Xu, F.-J. Reductionresponsive multifunctional hyperbranched polyaminoglycosides with excellent antibacterial activity, biocompatibility and gene transfection capability. Biomaterials 2016, 106, 134-143.

(62) Zimmermann, L.; Bussière, A.; Ouberai, M.; Baussanne, I.; Jolivalt, C.; Mingeot-Leclercq, M.-P.; Décout, J.-L. Tuning the antibacterial activity of amphiphilic neamine derivatives and comparison to paromamine homologues. J. Med. Chem. 2013, 56, $7691-7705$ 